\title{
Relationship between cognitive and sociodemographic aspects and verbal fluency of active elderly
}

\author{
Monique Coan Souza(1) \\ Flavia Rodrigues Bernardes ${ }^{(1)}$ \\ Camila Kretzer Machado(1) \\ Natalia Caroline Favoretto(2) \\ Natalia Gutierrez Carleto(2) \\ Cristina do Espírito Santo(2) \\ Aline Megumi Arakawa Belaunde ${ }^{(1)}$
}

1) Universidade Federal de Santa Catarina, Florianópolis, Santa Catarina, Brasil.

(2) Faculdade de Odontologia de Bauru, Universidade de São Paulo, Bauru, São Paulo, Brasil.

This study was conducted in the SpeechLanguage Pathology Department at the Federal University of Santa Catarina (UFSC), Florianópolis, Brazil.

Conflict of interests: Nonexistent

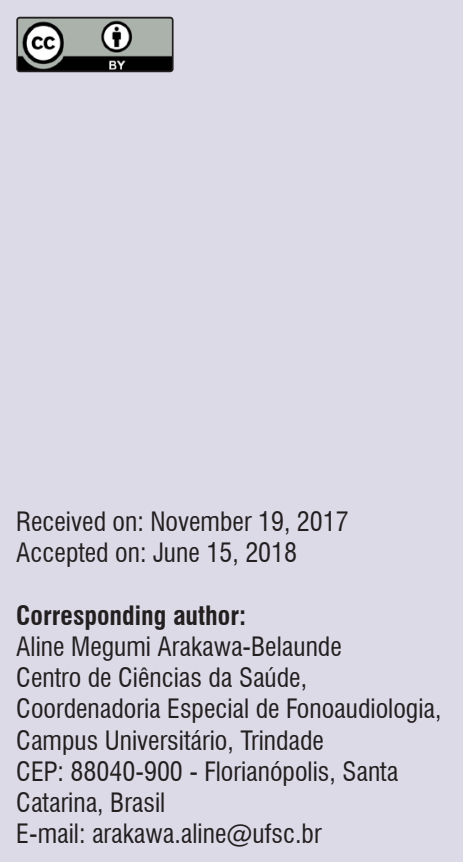

\section{ABSTRACT}

Purpose: to relate the cognitive aspects with sociodemographic data and the verbal fluency of the active elderly in a municipality in the south of Brazil.

Methods: an epidemiological study conducted with 386 elderly people participating in community groups of the municipality. Data were collected using a sociodemographic questionnaire, the Verbal Fluency Test (VFT) and the Mini-Mental State Examination (MMSE).

Results: most participants were women. The sample was characterized by people, predominantly with low schooling and income up to three minimum wages. It was possible to observe that the lower the years of schooling, the lower the monthly income, while the higher the age group, the worse the MMSE. Data of the present study showed significant relationships between the MMSE and the VFT.

Conclusion: the cognitive aspects analyzed through the MMSE were influenced by sociodemographic variables and the VFT. These aspects may contribute to the knowledge and monitoring of the cognitive aspects of those who participate in community groups.

Keywords: Elderly; Memory; Cognition; Epidemiology; Public Health 


\section{INTRODUCTION}

The aspects related to demographic and epidemiological transition have outlined the profile of the Brazilian population, focusing on the narrowing of the base and widening of the top of the age pyramid, characteristic of developed countries ${ }^{1}$. The latest demographic census indicated that in 2010 the country reached the mark of 190.8 million inhabitants and the number of elderly people in the year 2000 was 14 million; in 2010, this number was 19 million. By 2020, it will reach 28 million, and it is estimated that by 2050, it will total 64 million elderly people ${ }^{2}$.

The proportion of elderly people aged 80 years or more has been increasing and has important implications due to the higher frequency of comorbidities and a higher incidence of functional decline. This population may be denominated according to its age decade or as young elderly, middle-old elderly, older elderly and long-lived elderly ${ }^{3}$.

The aging process is characterized by several changes in the human body, and in old age, adaptation to the emotional, cognitive and behavioral dimensions is fundamental to obtain or maintain a standard of quality of life. According to the perspective of the World Health Organization (WHO), health is defined as "a state of complete physical, mental and social well-being and not only the absence of disease and infirmity"4. It is in the active aging with the continuity of the social practices of individual and collective welfare that there is the favoring of the adaptation to the process of modification, rebuilding the cultural and social role, solidifying the autonomy of the elderly ${ }^{5}$ while in parallel favoring the quality of life.

The definition of active aging applies to both individuals and population groups. It is the insertion of the elderly in the community, facing the opportunity to experience a better quality of life and healthy lifestyles, thus enabling the perception and participation in the civil, social and cultural aspects that go beyond being physically active or inserted in the labor market ${ }^{6}$. The good cognitive functionality of the elderly is considered an important sign of active aging and longevity, reaffirming the autonomy and self-care capacity of the elderly, influencing their decisions in respect to the possibility of continuing to live independently and safely. With the decline of cognitive abilities, it is a factor of increase in the risk of difficulties in the performance of activities of daily living ${ }^{7}$. Cognitive decline becomes one of the consequences of aging most feared by the elderly, requiring studies that investigate the risk factors associated with this aspect ${ }^{8}$.

Complaints of memory-related problems are present in the general population, but their prevalence tends to increase with advancing age. The elderly, when reporting memory impairment, are strongly concerned about the risk of such a condition developing into dementia?.

Dementia can be the result of various degenerative, vascular, neoplastic, infectious, toxic, metabolic and psychiatric conditions that are located in different parts of the brain, affecting different cognitive functions ${ }^{10}$. Among these, the most frequent dementia is Alzheimer's disease (AD), which affects $60 \%$ to $70 \%$ of these individuals ${ }^{11}$.

Dementia is an emerging issue that has aroused interest in studies by health professionals, a fact that occurs due to the increase in its incidence in the population in recent decades. Intercurrences do not only affect the patient, but also his or her family and caregivers. Attention relating to the patient involves factors such as memory loss, greater difficulty in concentrating and attention, loss of intellectual abilities, space-time disorientation, the eventual decrease in quality of life, growing difficulties in communicative relations, loss of the possibility of independence in activities of daily living and also the need for special care $^{12}$. One of the aspects that has an impact on this scenario is language, since the course of the disease can lead the individual to present alterations in speech, expression, comprehension, object naming, among others ${ }^{13}$.

The Verbal Fluency Test (VFT) $)^{14}$, widely used in Brazilian studies for the early identification of cognitive decline ${ }^{15}$, seeks to verify language, semantic memory and executive functions, evaluating the ability to search and retrieve data established in long-term memory. The VFT, which is based on categories, shows great sensitivity ${ }^{16}$ in distinguishing individuals without cognitive alterations from those in early stages of $A D^{17}$.

The Mini-Mental State Examination (MMSE) is one of the most widely used and researched tests in the world, used alone or incorporated into larger instruments, allowing the evaluation of cognitive function and the clinical profile of screening of dementia. Its application can be performed in clinical settings for the detection of cognitive decline, in the follow-up of the clinical features of dementia and in the follow-up to the response to treatment that the individual is submitted $^{18}$, as a screening instrument for dementia, 
not replacing a more detailed evaluation, but how evaluating several domains (time orientation, spatial orientation, immediate memory and recall, calculation, language and drawing copy), does so superficially. It has no diagnostic purposes, but rather to indicate which functions should be better investigated ${ }^{19}$.

Studying cognitive aging has become increasingly important, considering that the increase in the elderly population is already characteristic of developed countries, and has become the reality of developing countries, culminating in a growing demand in the area of public health. Researchers have begun to worry about the difficulties that can affect other cognitive functions beyond memory ${ }^{20}$. According to Converso and Lartelli $(2007)^{10}$, studies have pointed out that a predictor of $A D$ is mild cognitive impairment $(\mathrm{MCl})$. Therefore, it is fundamental to collect population data for further targeting of public policies and guidelines to the population.

Considering the aspects presented above, this study aimed to relate the cognitive aspects with sociodemographic data and the verbal fluency of active elderly in a municipality in the South of Brazil.

\section{METHODS}

The project was submitted and approved by the Committee of Ethics in Research with Human Beings of the State University of Santa Catarina - UDESC through CAAE: 34981514.2.0000.0118, in accordance with the recommendations of Resolution no. 466/2012 of the National Health Council. The elderly who accepted to participate in the study signed the term of free and informed consent.

This is an epidemiological study carried out in elderly community groups from a municipality in the South of Brazil. In this study, it is understood that a group community is a place where the elderly can have a space of strengthening, development and improvement of their potential, as well as the strengthening of bonds between participants and the community. Data collection was carried out from March to August 2015.

The total number of members enrolled in community groups, according to data provided by the Municipal Department of Social Assistance (MDSA), was 3,694 elderly people for the sample calculation, carried out according to Miot (2011) ${ }^{21}$, which considered a prevalence of $50 \%$ of elderly with a condition of interest, $95 \%$ confidence, $5 \%$ margin of error and possible losses of $10 \%$, with a minimum sample of 386 individuals. Statistical analysis was performed using the MedCalc program, version 16.2.0 (MedCalc Software bvba, Ostend, Belgium; https://www.medcalc.org; 2016).

The community groups with the largest number of participants registered in the relation to that offered by MDSA were selected according to each region of the studied municipality (north, south, central, east and continental region). The researchers contacted those in charge of each group so that they could subsequently participate in one of the meetings in loco. Elderly groups usually met weekly to perform activities such as bingo, dominoes, playing cards, dancing, painting and embroidery, and organizing events.

At these meetings, the elderly were invited by the researchers to participate in the study, and if accepted, subsequent visits were scheduled for the application of the research instruments in a private environment provided by the places where the groups were conducted.

Men and women aged 60 or over participated in the study, divided into groups of octogenarians and non-octogenarians. As exclusion criteria, self-reported aspects were taken into account, such as cognitive complaints that prevented them from responding to the proposed questionnaires, declaring visual and/or auditory deficit without correction, as well as presenting other conditions that compromise cognition such as depression (untreated) and psychiatric diseases. These aspects were signalized in dichotomous questions inserted in the sociodemographic questionnaire elaborated by the authors, containing questions about the age of participants, schooling (grouped in 0 to 4 years of study, 5 to 8 years of study, 9 to 11 years of study and greater than 11 years of study) and income (segmented into four groups, ranging from 1 to 3 minimum wages, 4 to 6 minimum wages, 7 to 9 minimum wages and equal or more than 10 minimum wages). This instrument was the first one to be applied to the knowledge of the sample and directed to the exclusion or not of the participant, as there were no scoring criteria. Also applied were the $\mathrm{VFT}^{14}$ and the $\mathrm{MMSE}^{19}$. The MMSE was selected in the treating of cognitive screening with no diagnostic attributes, and scoring followed the limits proposed according to the years of schooling of the participants: 20 points for those illiterate; 25 points for those with 1 to 4 years of schooling; 26 points for those with 5 to 8 years; 28 points for those with 9 to $11 ; 29$ points for individuals with schooling over 11 years ${ }^{19}$.

The other instrument applied was the Verbal Fluency Test (by semantic category animals/minute) whose cut-off points used were scores lower than nine 
animals for individuals with up to eight incomplete years of study and less than 13 for individuals with eight or more years of study, being indicative of cognitive dysfunction. The test consists of asking the individual to say as many animals as possible in one minute ${ }^{14}$. In both tests, the criterion "pass/fail" was used according to the scores obtained and the cut-off points explained.

\section{Statistical analysis}

The data were analyzed in a descriptive way by obtaining the mean and standard deviation of the numerical variable. The categorical variables were analyzed by obtaining the absolute and relative frequency.

Since the variables found did not present a normal distribution, the chi-square, Mann-Whitney, KruskalWallis tests, followed by the Dunn and JonckheereTerpstra tests and Spearman's correlation were used for inferential descriptive analysis. As a dependent variable, the MMSE scores (score and pass/fail) were used and the independent variables were schooling (grouped into four categories), age (octogenarians and non-octogenarians), VFT and monthly income (grouped into four categories). The analysis was performed using the MedCalc program, version 16.2.0, data considered significant with $p<0.05$.

\section{RESULTS}

A total of 386 elderly people participated in the present study, with a predominance of 370 (95.9\%) women. The study population had the mean age of 72.27 years (standard deviation of 7.90 years), median of 71 years, minimum and maximum age of 60 and 95 years, respectively. The prevalence of individuals with schooling up to four years of study and salary income between one and three minimum wages was observed (Table 1).

Table 1. Socioeconomic characterization of the sample. Florianópolis, SC, Brazil, 2015

\begin{tabular}{cccc}
\hline & & $\mathbf{N}$ & $\%$ \\
\hline \multirow{2}{*}{ Gender } & Females & 370 & 95.85 \\
& Males & 16 & 4.15 \\
\hline \multirow{2}{*}{ Age } & Octogenarians & 80 & 20.73 \\
& Non-octogenarians & 306 & 79.27 \\
\hline \multirow{3}{*}{ Schooling (years of study) } & 0 to 4 & 236 & 61.30 \\
& 5 to 8 & 39 & 10.12 \\
& 9 to 11 & 73 & 18.97 \\
\hline \multirow{3}{*}{ Income (minimum wages) } & $>11$ & 37 & 9.61 \\
& 1 to 3 & 79 & 70.13 \\
& 4 to 6 & 20 & 21.07 \\
& 7 to 9 & 13 & 5.33 \\
\hline
\end{tabular}

In the analysis performed for the MMSE, a mean of 23.99 points was obtained and in the VFT, mean of 12.63 animals (Table 2). Regarding the age group, with the division of elderly individuals and the proportion "older" (octogenarian more than 80 years), a significant difference ( $p<0.012$; Mann-Whitney test) was found in the analysis between the scores obtained in the MMSE. 
Table 2. Descriptive analysis of the Verbal Fluency Test and Mini Mental State Examination of the sample according to the years of schooling and monthly income. Florianópolis, SC, Brazil, 2015

\begin{tabular}{|c|c|c|c|c|c|c|c|c|c|c|c|c|}
\hline & & \multirow{2}{*}{ Scores } & \multicolumn{2}{|c|}{ Age (years) } & \multicolumn{4}{|c|}{ Years of schooling } & \multicolumn{4}{|c|}{ Monthly income } \\
\hline & & & $<80$ & $>80$ & 0 to 4 & 5 to 8 & 9 to 11 & $>11$ & 1 to 3 & 4 to 6 & 7 to 9 & $\geq 10$ \\
\hline \multirow{5}{*}{ VFT } & $x$ (SD) & 12.63 & 13.41 & 9.62 & 12.05 & 12.13 & 13.90 & 14.35 & 11.91 & 14.20 & 13.95 & 15.38 \\
\hline & $x(\Delta D)$ & $(4.45)$ & $(4.30)$ & (3.72) & $(4.53)$ & (3.64) & $(4.30)$ & $(4.26)$ & $(4.34)$ & $(4.38)$ & (3.97) & (2.79) \\
\hline & Median & 13 & 13 & 10 & 12 & 13 & 26 & 15 & 12 & 14 & 14 & 15 \\
\hline & Minimum & 0 & 0 & 3 & 0 & 3 & 5 & 6 & 0 & 6 & 5 & 10 \\
\hline & Maximum & 28 & 28 & 22 & 30 & 19 & 25 & 27 & 27 & 18 & 22 & 20 \\
\hline \multirow{5}{*}{ MMSE } & & 23.99 & 25.43 & 18.42 & 23.04 & 23.89 & 25.97 & 26.19 & 23.50 & 24.92 & 20.05 & 26.31 \\
\hline & $x(S D)$ & $(3.81)$ & $(2.41)$ & $(3.05)$ & $(3.80)$ & $(4.63)$ & $(2.45)$ & (2.81) & (3.98) & (3.20) & (3.35) & (2.63) \\
\hline & Median & 25 & 26 & 19 & 23 & 25 & 26 & 27 & 24 & 26 & 26 & 26 \\
\hline & Minimum & 9 & 21 & 9 & 9 & 10 & 19 & 6 & 9 & 10 & 18 & 23 \\
\hline & Maximum & 30 & 30 & 30 & 30 & 19 & 25 & 27 & 30 & 29 & 22 & 30 \\
\hline
\end{tabular}

Legend: VFT: Verbal Fluency Test; MMSE: Mini-Mental State Examination; x: mean; SD: standard deviation

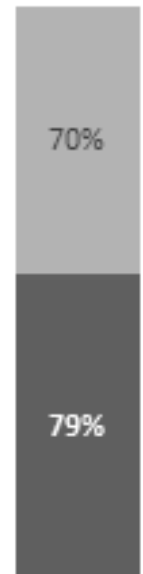

Passed VFT

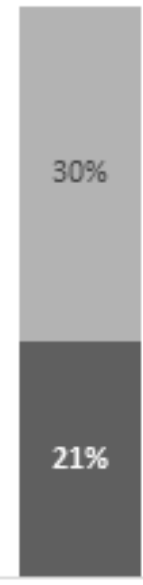

Failed VFT

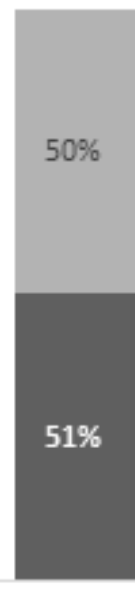

Passed MMSE

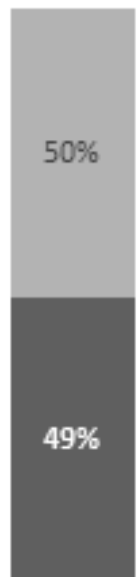

Failed MMSE

$$
\text { u }<80 \text { years } \quad>80 \text { years }
$$

Figure 1. Relative frequency of octogenarian individuals who passed/ failed verbal fluency test (VFT) and Mini-Mental State Examination (MMSE). Florianópolis, SC, Brazil, 2015

In addition, a significant difference can be found between the years of schooling and monthly income, as Table 3 indicates.

A statistically significant difference $(p<0.001)$ was found regarding the association between the aspect of pass/fail in the MMSE and schooling (chi-square test), with the percentage failure of individuals with less schooling being prevalent, as described in Figure 1. The years of schooling also influenced the results of the VFT, as shown in Figure 2. Confirming this difference, the trend test (Jonckheere-Terpstra test) was applied and found $p<0.001$. 


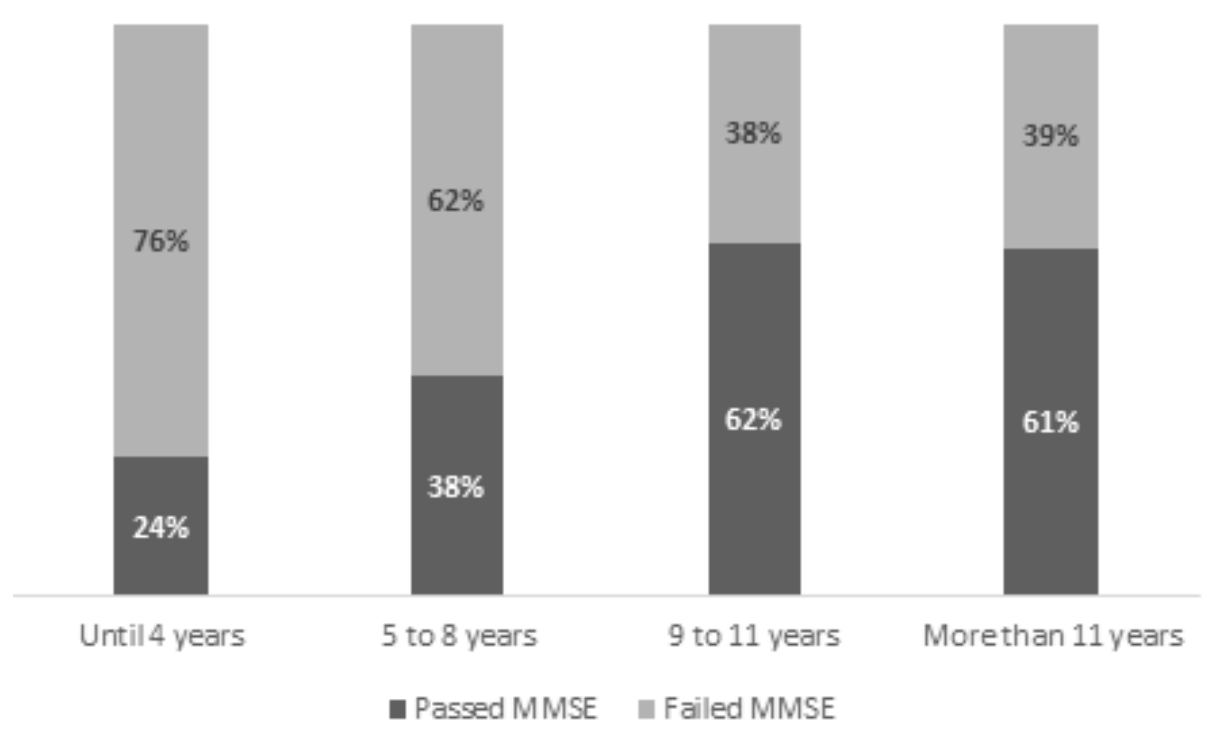

Figure 2. Relative frequency of individuals who passed/failed in the Mini-Mental State Examination (MMSE) according to years of schooling. Florianópolis, SC, Brazil, 2015

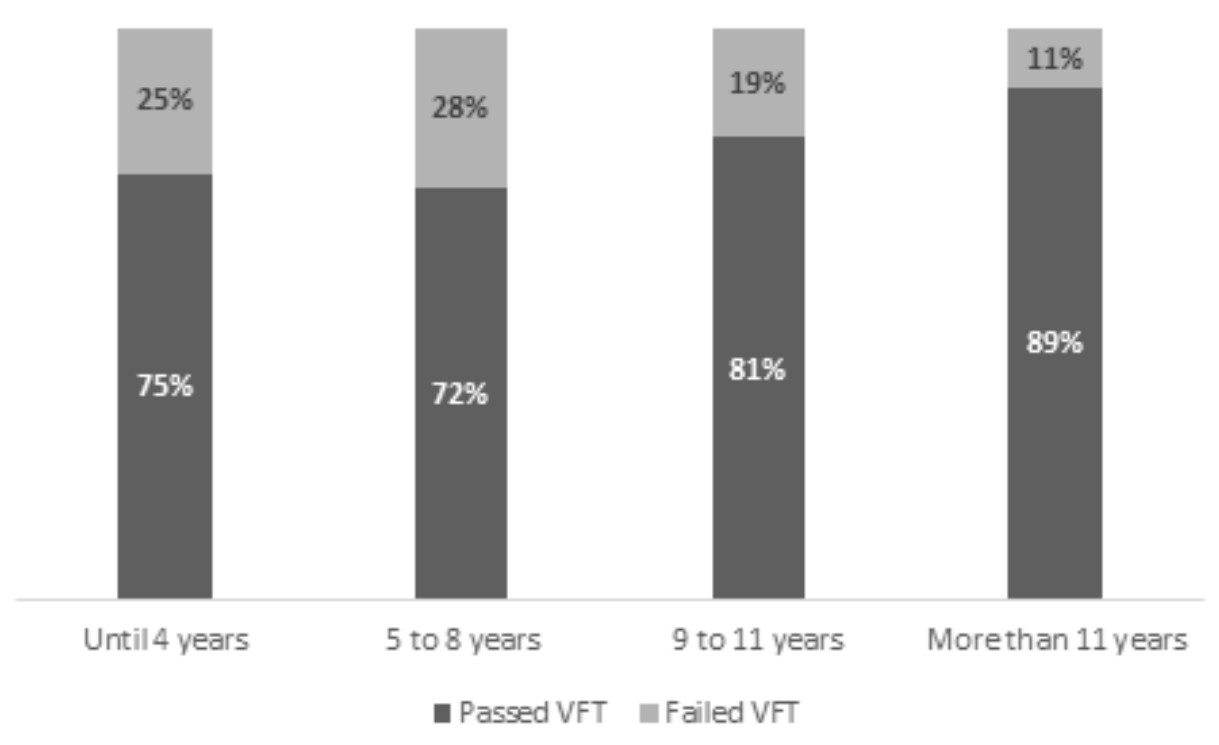

Figure 3. Relative frequency of individuals who passed/failed Verbal Fluency Test (VFT) according to years of schooling. Florianópolis, SC, Brazil, 2015

In the analysis of the scores between the MMSE and monthly income, it was possible to observe a significant difference ( $p<0.001$; Kruskal-Wallis test) among the group with income of 1 to 3 minimum wages with the groups with income of 4 to 6 and equal or greater than 10 minimum wages (Dunn's test), and found $p<0.001$ when verifying the trend in monthly income increase and MMSE scores (Jonckheere-Terpstra test).
Complementing the data presented in Figures 4 and 5 regarding the relative frequency of individuals who have passed and failed in the MMSE and VFT, it is emphasized that, although both tests complement the diagnosis of dementia, they evaluate different cognitive abilities. Thus, in the present study, the unfavorable performance in one of the tests did not necessarily adversely affect the overall score presented by the other instrument. 


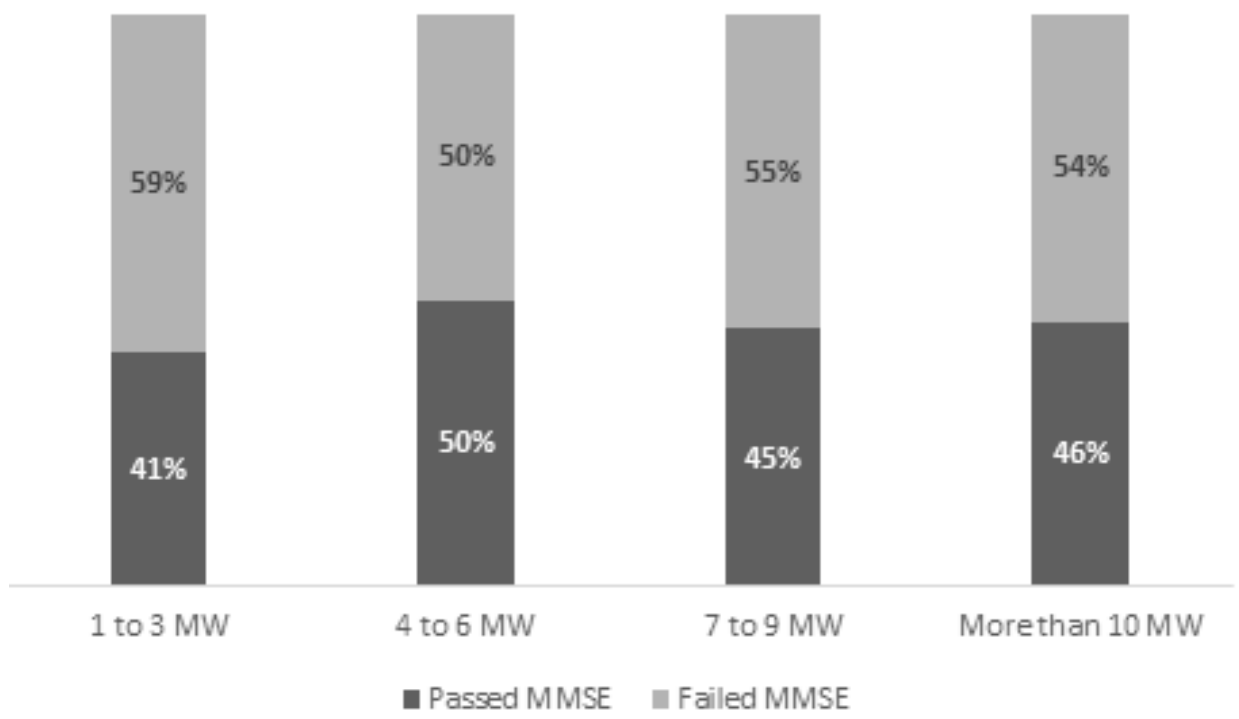

Figure 4. Relative frequency of individuals who have passed/failed in the Mini-Mental State Examination (MMSE) according to monthly income in minimum wages (MW). Florianópolis, SC, Brazil, 2015

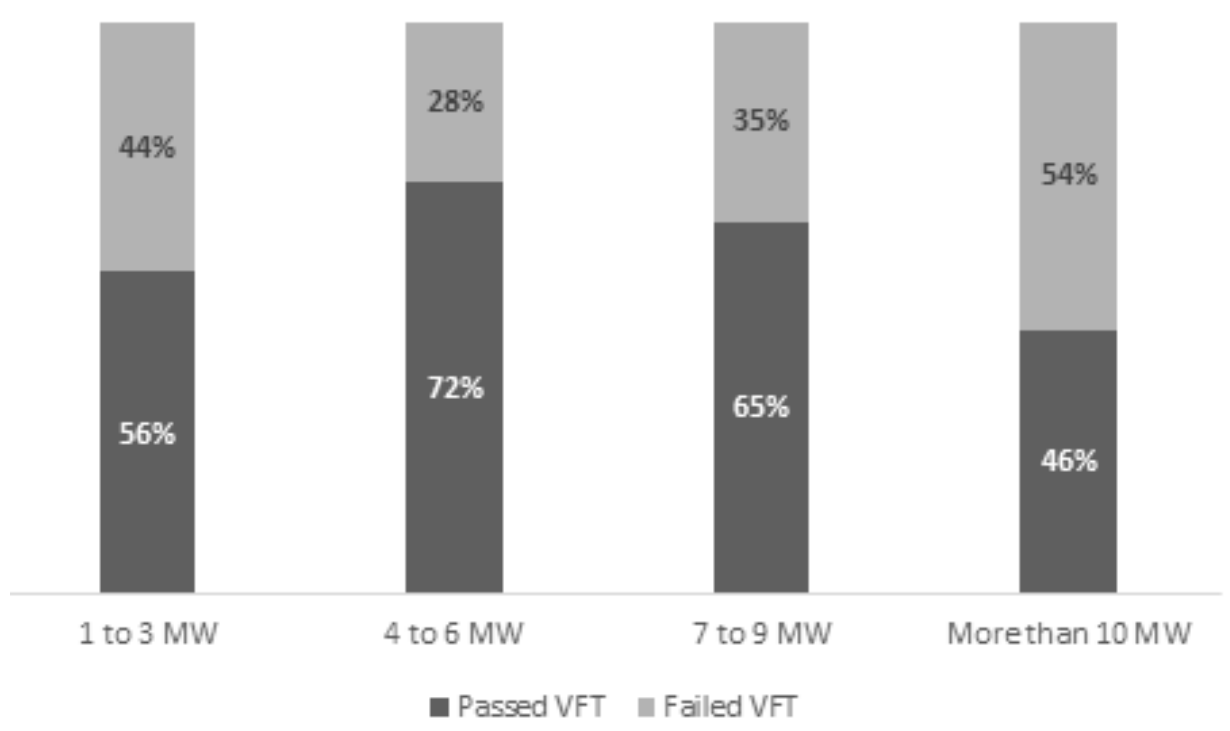

Figure 5. Relative frequency of individuals who passed/failed Verbal Fluency Test (VFT) according to monthly income in minimum wages (MW). Florianópolis, SC, Brazil, 2015

Table 3. Inferential analysis of the Mini-Mental State Examination and age, schooling, monthly income and Verbal Fluency Test. Florianópolis, SC, Brazil, 2015

\begin{tabular}{lcc}
\hline Associated variables & Statistical test & p value (r) \\
\hline Age octogenarians and non-octogenarians x MMSE (pass/fail) & chi-square & 0.899 \\
Age octogenarians and non-octogenarians x MMSE (score) & Mann-Whitney & 0.012 \\
Schooling x MMSE (pass/fail) & chi-square & 0.003 \\
Schooling x MMSE (score) & Kruskal-Wallis & $<0.001$ \\
Monthly income x MMSE (pass/fail) & chi-square & 0.596 \\
Monthly income x MMSE (score) & Kruskal-Wallis & $<0.001$ \\
VFT (pass/fail) x MMSE (pass/fail) & chi-square & 0.002 \\
VFT (scores) x MMSE (score) & Pearson correlation coefficient & $<0.001(\mathrm{r}=0.478)$ \\
\hline
\end{tabular}

Legend: VFT: Verbal Fluency Test; MMSE: Mini-Mental State Exam; $x$ : mean; SD: standard deviation 
Association and correlation were found between the MMSE and the VFT (chi-square test and Spearman's correlation) with $p=0.002$ and $p<0.001(r=0.478)$, respectively. The community groups were organized according to the regions of the studied municipality. No significant difference was found in the association between them and the MMSE $(p=0.648)$, as well as between the VFT $(p=0.360)$.

\section{DISCUSSION}

In the sample of the present study, the majority of participants were females, an aspect that meets the trend reported in the literature ${ }^{18,22,23}$ as well as the process of feminization of aging related to the fall in fertility rates and population mortality ${ }^{24}$. One of the causes of this panorama may be related to the fact that women tend to marry older men who, associated with a higher male mortality than females, increase the probability of survival of the woman in relation to her spouse. Adding to that is the tendency of women to attend social spaces, as opposed to men, who in addition to little participation, are considered financial providers of the home ${ }^{22}$.

The mean score obtained in the MMSE, in the present study resembles others such as that of de Leite et al. (2012) ${ }^{22}$, but with greater amplitude. It was possible to observe that the score of the MMSE is related to variable age when the octogenarian individuals were analyzed, who obtained a lower score in the test than the non-octogenarians, corroborating that of other studies ${ }^{22,25}$, which also obtained results of age influencing in the test. According to Valle et al. $(2009)^{26}$, age is one of the most important determinants of cognitive decline.

Schooling was another factor that had a strong influence on the results obtained in the MMSE, in which data showing the participants having a low level of schooling presented a lower score in the test. This aspect is also found in studies ${ }^{18,24}$ in which the population with low educational levels obtained significant results because they failed in the MMSE test. The analysis performed for the years of schooling and the VFT also showed a relation when the obtained scores were analyzed.

It has been shown that the higher the schooling level, the better the cognitive performance, making the brain more resilient and flexible in the face of the effects of diseases or the common alterations caused by aging. The level of schooling is fundamental to the fact that the elderly with less schooling perform worse in almost all cognitive tests. According to the literature, educational experience and the use of more complex cognitive abilities can strengthen the cognitive reserve and preserve both the cognition and the functionality of the individual. Thus, formal education, and later occupational professional occupation, may be essential in the formation of long-term cognitive resources, which are protective factors against early onset and manifestation of neurodegenerative diseases such as $A D^{27}$.

When analyzing the relationship between monthly income and the scores obtained in the MMSE, it was possible to observe a significant difference of the group with the lowest income range, in relation to the other two ranges with higher income, signaling that elderly people with low monthly income are more likely to present a cognitive decline. The factors that may be associated with the results of the presented data are low education level, lack of attention to health, and low incentive to affective and social relations ${ }^{22}$.

The data of the present study presented significant relations between the MMSE and the VFT. The VFT and the MMSE are tests contemplated in the Primary Care Guidebook of the Brazilian Ministry of Health ${ }^{28}$, being widely applied, fast, practical, easy application and with simple scoring, which can aid in the measurement of cognitive decline even in the early stages of demential syndromes. Given the importance of language for the diagnosis of dementia, a longitudinal study ${ }^{29}$ found that patients who progressed to $A D$ started with a decline in the VFT twelve years before being diagnosed with dementia.

Bringing up the theme related to the prevention of impairments, it is believed that mental activities become one of the protective factors of cognitive functions. The mental stimulus associated with physical and social factors is based on the promotion of elderly health, and consequently, the prevention of clinical profiles of dementia regardless of severity ${ }^{30}$.

Thus, due to growth of the aging population, the surveillance of the health aspects of the elderly has been intensified in the last decades and is recognized as a relevant public health theme ${ }^{24}$. As a result, it is possible to provide subsidies to assist in directing the public health actions of the municipality studied.

The dementia process in the elderly population is one of the main public health problems in Brazil. Therefore, the importance of diagnosis and early approach is observed, aiming at a better therapeutic response, for a better quality of life of this group, and consequently, of their relatives ${ }^{11}$. 
For a better approach of patients with dementia, investments are necessary in increasing demand which accompanies the growth of this population. Any policy aimed at the elderly must take into account the need for autonomy, participation, care, self-satisfaction and functional capacity. The presence of specialized health centers and easy access for the elderly, together with publicity campaigns aimed at raising the awareness of family members and caregivers of the elderly, is becoming increasingly necessary in order to both avoid neglect and in the appearance of dementia. Such investments could help public health policies, reducing expenses with the installation of chronic conditions of worse prognosis ${ }^{31}$.

The approach given to the active elderly is understood as one of the limitations of the study, therefore, it is not possible to generalize the findings to all individuals who grow older. Thus, the development of studies that cover the population of the elderly of different regions of the country is necessary, to increase the knowledge about the subject studied. Additionally, studies can be carried out on interventions that the elderly receive as well as their impact on their cognitive performance.

\section{CONCLUSION}

It could be observed that the cognitive aspects analyzed through the Mini-Mental State Exam were influenced by age, schooling and monthly income, in addition to having a significant relationship with the Verbal Fluency Test. Such aspects can contribute to the knowledge and surveillance of the cognitive aspects of those who participate in community groups.

\section{REFERENCES}

1. Vasconcelos AMN, Gomes MMF. Transição demográfica: a experiência brasileira. Epidemiol Serv Saúde. 2012;21(4):539-8.

2. Instituto Brasileiro de Geografia e Estatística. Projeção da população do Brasil por sexo e idade para o período 1980-2050: revisão 2008. Rio de Janeiro: IBGE; 2008. [acesso em 2014 jun. 23]. Disponível em: <http://www.ibge.gov. br/home/estatistica/populacao/projecao_da_ populacao/2008/projecao.pdf>.

3. Brasil. Ministério da Saúde. Secretaria de Atenção à Saúde. Departamento de Atenção Básica. Envelhecimento e saúde da pessoa idosa. Brasília (DF): MS; 2006.
4. Organização Mundial de Saúde. Programme on mental health - WHOQOL User Manual. Division of Mental Health and Prevention of Substance Abuse. 1998.

5. Pereira KCR, Alvarez AM, Traebert JL. Contribuição das condições sociodemográficas para a percepção da qualidade de vida em idosos. Rev Bras Geriatr Gerontol. 2011;14(1):85-95.

6. World Health Organization. Envelhecimento ativo: uma política de saúde. Brasília: Organização Pan-Americana da Saúde, 2005.

7. Irigaray $\mathrm{TQ}$, Schneider RH, Gomes I. Efeitos de um treino cognitivo na qualidade de vida e no bem-estar psicológico de idosos. Psicol Reflex Crít. 2011;24(4):810-8.

8. Di Nucci FRCF, Coimbra AMV, Neri AL, Yassuda MS. Ausência de relação entre hipertensão arterial sistêmica e desempenho cognitivo em idosos de uma comunidade. Rev Psiq Clín. 2010;37(2):52-6.

9. Guerreiro TC, Veras R, Motta LB, Veronesi AS, Schmidt S. Queixa de memória e disfunção objetiva de memória em idosos que ingressam na Oficina da Memória ${ }^{\circledR}$ na UNATI/UERJ. Rev Bras Geriatr Gerontol. 2006;9(1):7-20.

10. Converso MER, lartelli I. Caracterização e análise do estado mental e funcional de idosos institucionalizados em instituições públicas de longa permanência. J Bras Psiquiatr. 2007;56(4):267-72.

11. WHO. World Health Organization. Dementia: a public health priority. Geneva: World Health Organization; 2012.

12. Mac-Kay APMG. Distúrbios de linguagem: demência. In: Russo IP (Org). Intervenção fonoaudiológica na terceira idade. Rio de Janeiro: Revinter, 2004. p.121-31.

13. Araujo CLO, Nicoli JS. Uma revisão bibliográfica das principais demências que acometem a população brasileira. Rev Kairós. 2010;13(1):231-44.

14. Brucki SMD, Maleiros SMF, Okamoto IH, Bertolucci PHF. Dados normativos para o teste de fluência verbal categoria animais em nosso meio. Arq Neuropsquiatr. 1997;55(1):56-61.

15. Costa SAA, Miotto EC, Lucia MCS, Scaff M. Atividade física, envelhecimento e o desempenho no teste de fluência verbal categoria animais. Psicol Hosp. 2013;11(1):88-102.

16. Eastman JA, Hwang KS, Lazaris A, Chow N, Ramirez L, Babakchanian S et al. Cortical thickness and semantic fluency in Alzheimer's disease and 
mild cognitive impairment. American Journal of Alzheimer's Disease. 2013;1(2):81-92.

17. Brucki SMD, Rocha MSG. Category fluency test: effects of age, gender and education on total scores, clustering and switching in brazilian portuguese-speaking subjects. Braz J Med Biol Res. 2004;37(12):1771-7.

18. Lourenço RA, Veras RP. Mini-Mental State Examination: psychometric characteristics in elderly outpatients. Rev Saúde Publica. 2006;40(4):712-9.

19. Brucki SMD, Nitrini R, Caramelli P, Bertolucci PHF, Okamoto IH. Sugestões para o uso do Mini-Exame do Estado Mental no Brasil. Arq Neuropsiquiatr. 2003;61(3-B):777-81.

20. Argimon IIL. Aspectos cognitivos em idosos. Aval Psic. 2006;5(2):243-5.

21. Miot HA. Tamanho da amostra em estudos clínicos e experimentais. J Vasc Bras. 2011;10(4):275-8.

22. Leite MT, Hildebrandt LM, Kirchner RM, Winck MT, Silva LAA, Franco GP. Cognitive and health conditions in elderly participants in recreation and leisure activities centers. Rev Gaúcha Enferm. 2012;33(4):64-71.

23. Vitiello APP, Ciríaco JGM, Takahashi DY, Nitrini R, Caramelli P. Avaliação cognitiva breve de pacientes atendidos em ambulatório de neurologia geral. Arq Neuropsiquiatr. 2007;65(2-A):299-303.

24. Soares C. Envelhecimento populacional e as condições de rendimento das idosas no Brasil. Rev. Gênero. 2013;12(2):167-85.

25. Domiciano BR, Braga DKAP, Silva PN, Vasconcelos TB, Macena RHM. Escolaridade, idade e perdas cognitivas de idosas residentes em instituições de longa permanência. Rev Neurocienc. 2014;22(3):330-6.

26. Valle EA, Costa EC, Firmo JOA, Uchoa E, Costa MFL. Estudo de base populacional dos fatores associados ao desempenho no Mini Exame do Estado Mental entre idosos: projeto Bambuí. Cad Saúde Publica. 2009;25(4):918-26.

27. Coelho FGM, Vital TM, Novais IP, Costa GA, Stella F, Galduroz RFS. Desempenho cognitivo em diferentes níveis de escolaridade de adultos e idosos ativos. Rev Bras de Geriatr Gerontol. 2012;15(1):7-15.

28. Brasil. Ministério da Saúde. Secretaria de Atenção à Saúde. Departamento de Atenção Básica. Envelhecimento e saúde da pessoa idosa. Brasília: Ministério da Saúde, 2006. 192 p. il. - (Série
A. Normas e Manuais Técnicos) (Cadernos de Atenção Básica, n. 19).

29. Montiel JM, Cecato JF, Bartholomeu D, Martinelli JE. Testes do desenho do relógio e de fluência verbal: contribuição diagnóstica para o Alzheimer. Revista Psicologia: teoria e prática. 2014;16(1):169-80.

30. Soares E. Memória e envelhecimento: aspectos neuropsicológicos e estratégias preventivas. Psicologia. 2006;1-8 [acesso em 2017 ago 20]. Disponível em: http://www.psicologia.pt/artigos/ textos/A0302.pdf

31. Pereira KKG, Oliveira LP, Lucena ALR, Freitas $F F Q$, Vieira KFL. Rastreio de demência através do Mini Exame do Estado Mental e Teste do Relógio em idosos. Rev Ciênc Saúde Nova Esperança. 2014;12(2):26-35. 